\title{
Non-linear Impact of the Short Circuit Impedance Selection on the Cost Optimized Power Transformer Design
}

\author{
Tamás Orosz ${ }^{1 *}$, Zoltán Ádám Tamus² \\ 1 Department of Theory of Electrical Engineering, Faculty of Electrical Engineering, University of West Bohemia, 30100 Pilsen, \\ Univerzitní 2732/8, Czech Republic \\ 2 Department of Electric Power Engineering, Faculty of Electrical Engineering, Budapest University of Technology and Economics, \\ H-1521 Budapest, P.O.B. 91, Hungary \\ *Corresponding author, e-mail: orosz.tamas@vet.bme.hu
}

Received: 23 November 2019, Accepted: 03 December 2019, Published online: 17 February 2020

\begin{abstract}
Since the electrical machine design is a complex task it can be divided into sub-problems, e.g. preliminary and final design processes and checking of the final design. This paper deals with the preliminary design process, which provides the key-design parameters of the electrical machine. Traditionally, these electrical machine models in preliminary design phase neglect or use oversimplified insulation system models and the tap changing selection is not involved during the calculation of key-design parameters. The aim of this study is to assess the effect of the insulation distance minimization and tap-changing on the key design parameters of a costoptimized large power transformer. For this purpose, the paper shows some examples, where the cost optimal design - in contrast to the classical insulation design rule - contains larger insulation distances than the possible minimum values. The effect of tapchanging methods are also investigated. These cost optimization made by a verified, metaheuristic method-based transformer optimization algorithm. The results show involving the insulation design and tap-changing selection into the preliminary design process can provide more economical designs.
\end{abstract}

Keywords

power transformer, design optimization, mathematical optimization

\section{Introduction}

The intense competition on the electrical equipment market makes the manufacturers reduce production costs. Since the material cost is the major cost component of electrical machines, there is an essential need to decrease the material usage in the final construction. Nevertheless, decreasing the mass of materials (iron-core, copper and insulating materials) is a complex design problem, every step forward results in elevated operation stresses, e.g., decreasing of the volume of iron core or winding increases the magnetic induction and current density, respectively. Increased magnetic induction or current density generates higher loss, which increases the operation temperature of the active parts. Higher temperature fosters the degradation of equipment resulting in shorter lifetime [1-4]. Since, the power transformers are not mass produced items, they are manufactured by custom design accordingly the design process is a labor intensive task. In tendering, the price calculation cannot be based a final, detailed design of a transformer.
Therefore, their complex design task is usually treated as three sub-problems: the preliminary and final design processes and checking of the final design.

All these stages have well determined role in the whole design process. The purpose of the preliminary design (or pre-conception) stage to determine the key-design parameters, i.e. the most characteristic parameters of the transformer.

In this stage, the factors, which have greatest influence on the dimensions of the active part are considered. Since the output of these active part models [3-11] contains enough information to estimate and compare the final price of potential transformers. This stage plays a very important role in the whole design process because based on these output parameters, the tender price is also calculated. After successful tendering, the final design is worked out in details. After both design stages, the final design is checked by an independent designer. 
With increasing competition, the tenders have to be submitted in a short period of time hence the speed of competitive but profitable tender price calculation is the key issue. This emphasizes the importance of the preliminary design stage. Due to numerous mechanical, thermal and electrical constraints, the determination of the cost-optimal key-design parameters belong to the most general non-linear mathematical optimization problems and several solution methods have been published in the literature [5]. In classical design approach of transformers, the insulation system, winding arrangement and tap changing are designed in the final design phase hence they effect on the tender price is necessarily neglected.

This paper introduces the complexity and non-linearity effect of involving the insulation and tap changing design in the preliminary design phase. For this purpose, the cost optimal design of a core-type large power transformer has been examined by a newly developed meta-heuristic algorithm worked out by the authors [10]. The accuracy of this algorithm is verified by FEM [10, 11] and in the last years, a user-friendly version of this code has been started to use in the industry. In Section 2, the calculation method is introduced. Then the non-linearity effect of insulation gap distance, winding arrangement and tap charging method is examined and the results are evaluated.

\section{Method of comparison}

\subsection{Total Cost of the Ownership}

The objective of the following optimization is the lifetime, i.e. Total Cost of the Ownership (TCO) [12]. This quantity contains not only the manufacturing cost of the transformer but also the cost of the operation during the transformer's lifetime. The manufacturing costs and the key-design parameters of the transformer are calculated for active part of the transformer, because its dimensions determine the total cost of the equipment adequately. The TCO of the transformer is determined in the following way:

$$
\mathrm{TCO}=K_{1} P_{N l l}+K_{2} P_{l l}+\sum_{k=0}^{n} C_{k} M_{k},
$$

where the TCO is calculated in $€$. Symbols $K_{1}$ and $K_{2}$ represent the capitalization factors for the no-load loss and load losses in $€ / \mathrm{kW}$ units. Quantities $P_{N l l}$ and $P_{l l}$ mean the sum of the load and the no-load losses in $\mathrm{kW}$ units, which is generated in the active parts of the transformer, $C_{k}$ represents the specific cost of an active part element in $€ / \mathrm{kg}$, while $M_{k}$ is the mass of the $k^{\text {th }}$ element of the core or the winding system in $\mathrm{kg}$.

\subsection{Transformer model}

The geometrical and electrical properties of transformer are modelled by the key-design parameters (Table 1). This pre-concept model contains a lot of simplifications, e.g. the windings and cross section of the core are represented by their boundary and their copper or core filling factor. These assumptions are widely accepted in industry, they estimate the copper and core losses with the required accuracy and significantly simplify the multifarious possible core and winding layouts. This preliminary design transformer model defines the outer boundary of the main elements of the active parts, which is enough for the cost calculation and preposition. Knowledge of these key-design parameters accelerates the engineer's work and the detailed design parameters can be determined easily, using the standard practices (Fig. 1).

\subsection{Metaheuristic search}

In this paper, a geometric programming based on the metaheuristic algorithm [10, 13-15] has been used to solve the mathematical model of this preliminary design cost optimization problem. The motivation to make a geometric programming-based solver for this transformer optimization design problem is twofold. Firstly, the

Table 1 The optimized key-design parameters of the applied preliminary design transformer model

\begin{tabular}{|c|c|c|c|}
\hline Physical quantity & Dimension & & Variable \\
\hline Core diameter & & $\mathrm{mm}$ & $D_{\text {core }}$ \\
\hline Flux density in the core & & $\mathrm{T}$ & $B$ \\
\hline Main insulation distance & & $\mathrm{mm}$ & $g$ \\
\hline \multirow{3}{*}{ Current density } & inner & $\mathrm{A} / \mathrm{mm}^{2}$ & $j_{\text {in }}$ \\
\hline & outer & $\mathrm{A} / \mathrm{mm}^{2}$ & $j_{o u}$ \\
\hline & Regulating & $\mathrm{A} / \mathrm{mm}^{2}$ & $j_{r e g}$ \\
\hline Winding height & inner & $\mathrm{mm}$ & $h_{\text {in }}$ \\
\hline Load loss & $\mathrm{kW}$ & \multirow{7}{*}{$\mathrm{mm}$} & $P_{l l}$ \\
\hline No-load loss & $\mathrm{kW}$ & & $P_{N l l}$ \\
\hline $\begin{array}{l}\text { Width of the working } \\
\text { window }\end{array}$ & & & $s$ \\
\hline Core Mass & $\mathrm{t}$ & & $M_{\text {core }}$ \\
\hline Tank length & $\mathrm{mm}$ & & $L$ \\
\hline Tank width & $\mathrm{mm}$ & & $W$ \\
\hline Tank height & $\mathrm{mm}$ & & $H$ \\
\hline \multirow{3}{*}{ Winding Thickness } & inner & $\mathrm{mm}$ & $t_{i n}$ \\
\hline & outer & $\mathrm{mm}$ & $t_{\text {ou }}$ \\
\hline & Regulating & $\mathrm{mm}$ & $t_{r e g}$ \\
\hline \multirow{3}{*}{ Mean radius } & inner & $\mathrm{mm}$ & $r_{i n}$ \\
\hline & outer & $\mathrm{mm}$ & $r_{\text {ou }}$ \\
\hline & Regulating & $\mathrm{mm}$ & $r_{r e g}$ \\
\hline
\end{tabular}




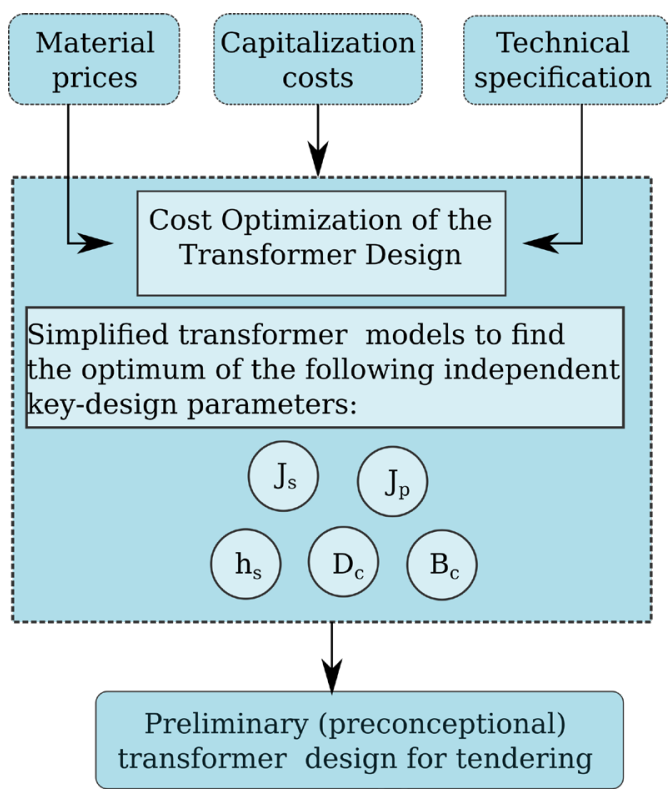

Fig. 1 Three steps of classical transformer design $[1,2]$

modern interior-point based GP solvers are fast and robust. Secondly, the mathematical modelling rules of the geometric programming guarantee that the obtained solution is the global optimum $[16,17]$. Nonetheless, the formalism of this branch of nonlinear mathematical optimization methods is quite restrictive. The expressions of the equality and inequality constraints have to be formulated in a special mathematical formulae called monomials (Eq. (2)) and posynomials (Eq. (3)):

$$
\begin{aligned}
& m(x)=c_{g} x_{1}^{\alpha_{1 k}} x_{2}^{\alpha_{2 k}} \ldots x_{n}^{\alpha_{n k}}, \\
& p(x)=\sum_{k} c_{k} x_{1}^{\alpha_{1 k}} x_{2}^{\alpha_{2 k}} \ldots x_{n}^{\alpha_{n k}},
\end{aligned}
$$

where $c_{k}>0$, the $\alpha$ parameters are real numbers and the values of the $x$ variables have to be positive. The cost optimization problem of a shell-type power transformer can be formulated in the required special form of the geometric programming [18]. However, this branch of mathematical optimization methods cannot been used in the case of core-type power transformers, where a strict requirement is prescribed for the short circuit impedance [10, 14].

In case of core-type power transformers the short-circuit impedance is defined by the following formula:

$$
\mathrm{SCI}[\%]=\frac{2 \pi \mu_{0} f P_{w l}}{U_{T}^{2}(h+0.32 s)}\left(\frac{R_{i n} t_{i n}}{3}+\frac{R_{o u} t_{o u}}{3}+R_{m} g\right),
$$

where the $\mathrm{SCI}$ is given in $\%, U_{T}$ means the turn voltage and $P_{w l}$ is the built-in power in a wounded limb. In this type of transformer core it holds that $P_{w l}=P_{\text {phase }}$, where
$P_{\text {phase }}$ is the phase power of the transformer, $R_{i n}$ and the $R_{\text {ou }}$ are the mean radiuses of the inner and the outer windings, while tin and the tou are the radial thickness of these, main windings. Finally, $R_{m}$ is the mean radius of the main gap of the transformer, which thickness is represented by $g$.

As it can be seen from Eq. (4) and Table 1, these formulae are not monomial (Eq. (2)) expressions of the variables as required. In this case, a lower and an upper bound can be defined for Eq. (4). However, as shown in [10, 14], a lower limit cannot been formulated in the posynomial format. As it can be seen in Fig. 2, the application of this lower limit is essential in the practical cases. Fig. 2 depicts the dependence of the transformer's TOC from the prescribed value of the short-circuit impedance. It can be seen from this practical example that the TOC has an optimal value as a function of SCI, which usually lower than defined by the standard or required by the customer. Therefore, the upper limit does not tighten the search space in most practical cases.

To solve this problem, the model based on geometric programming was combined with Branch and Bound search (BB) [13]. The BB executes a binary search in sense that the solution space is divided into several subspaces, which can be described by appropriate convex terms $[13,14]$. The BB can produce large number of sub-cases, but the $\mathrm{BB}$ is usually quite efficient in practice because it employs advanced techniques to remove certain parts of the search tree before evaluation. The correctness of the provided solution is verified by a FEM [13]. To proof the performance and the accuracy of the metaheuristic search - viz. the algorithm finds the key-design parameters, which are related to the global optimum - is compared by iterative and evolutionary optimization method-based algorithms [11]. The general solution for core-type power transformers are deeply described in [10].

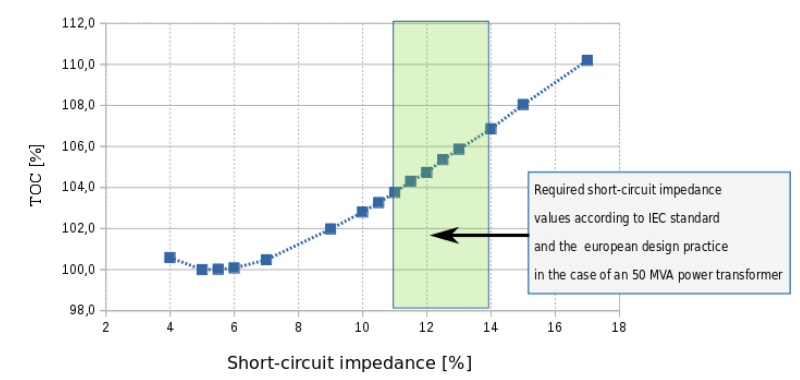

Fig. 2 The function of the minimal TOC value at different SCI values in the case of a 50 MVA power transformer 


\section{Nonlinearities in transformer design}

\subsection{Minimizing the insulation distances}

The insulation design, despite its importance, inevitably plays a minor role in this process. Usually the insulation of a power transformer is designed in the final design phase. The insulation system of the power transformer is designed with a given safety factor i.e. the ration of maximum permissible field strength of the insulating material and the electric field strength in operation [19]. This safety factor is usually determined by the simplified economic optimization of manufacturing costs and failure costs (Fig. 3). This approach — appeared couple of decades ago [20] suggests the minimum value of the failures and manufacturing costs provide the optimal insulation distance.

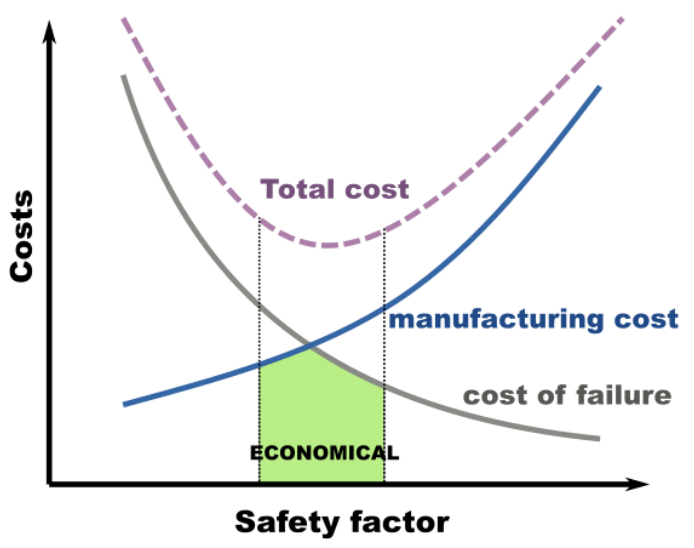

Fig. 3 The classical insulation design rule assumes the manufacturing cost of an electrical machine is proportional to insulation volume, while the failure rate (costs of failure) decreases. Hence, the economically optimal insulation system can be found near the minimum of the resultant function of the manufacturing and failure costs. $[4,19,20]$
There is a lot of interest in the electrical machine industry to find lower insulation distances to decrease the volume of insulation and the whole equipment to reduce the material costs and achieve a more competitive design [21-23].

The aim of this example to demonstrate that — in contrast to this classical insulation design approach the minimization of the insulation volume does not lead to the cheapest transformer design in every case.

In this example 7.5 MVA power transformer with $13.8 \mathrm{kV} / 4.16 \mathrm{kV}$ voltage ratio is selected. The network frequency is $60 \mathrm{~Hz}$, the required short circuit-impedance is $5.5 \%$. The parameters are selected according to the requirement of the North American market [24]. The TOC is calculated in two different cases by the following capitalization factors: $K_{1}=8000 € / \mathrm{kW}$ and $K_{2}=2000 € / \mathrm{kW}$. The results of the optimization are illustrated in the Fig. 4. The optimization has been made in two different ways, in the second case the optimization algorithm searched the minimum of the TOC by the minimum value of the main gap. As it can be seen from the results, in this case the algorithm has found the optimal design with an increased main gap distance. The two results are very close to each other, the difference between the two different TOC is about $2 \%$, but the difference between the shape of the two designs is significant. Moreover contrasting to the classical insulation design approach, transformer having higher gap distance has lower TOC value. This result suggests the insulation design has to be involved in the preliminary design phase.
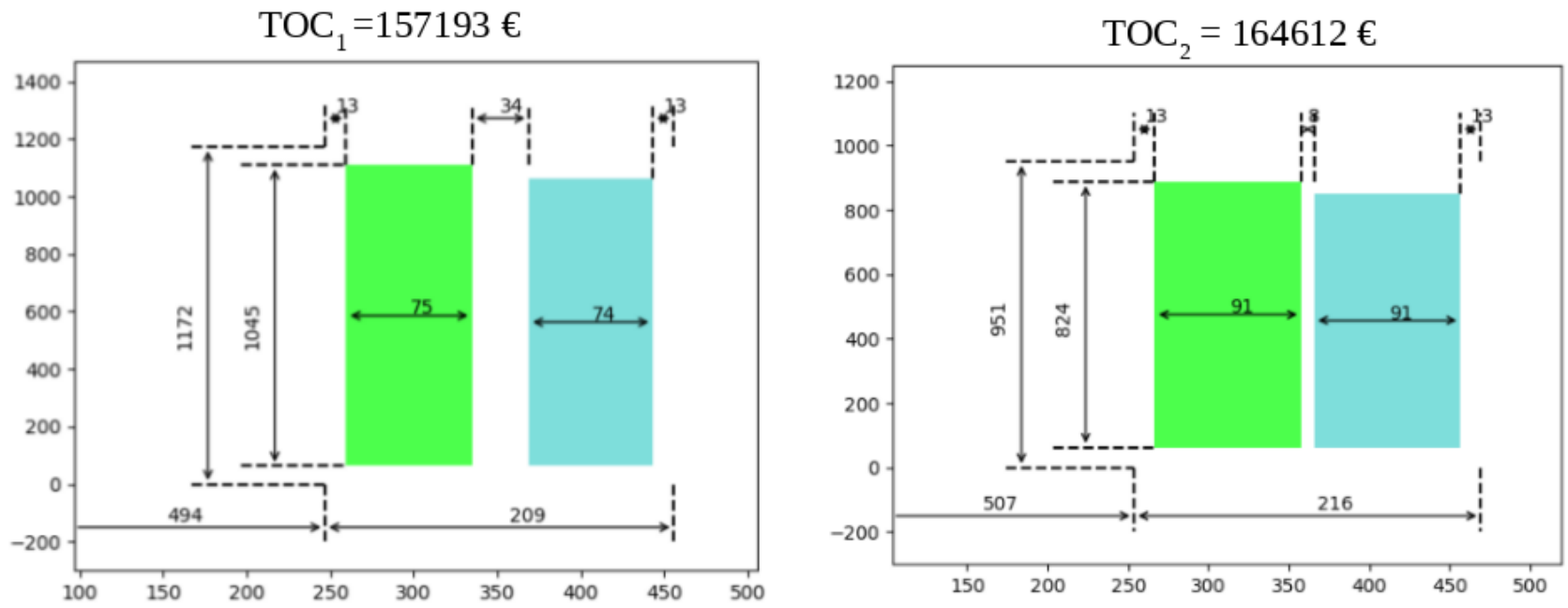

Fig. 4 Results of the optimization of 7.5 MVA transformer without fixing main gap distance and with fixed main gap distance 


\subsection{Winding order}

Most of the modern regulated power transformer's winding systems contain physically three separate windings per phase: Low Voltage (LV), High Voltage (HV) and Regulating (Reg) winding. The Regulating winding is not an electrically independent winding system, because it is connected to the same electrical circuit as the regulated winding. In the European grid the regulated winding is usually the HV. In accordance with the classical insulation design principles, the winding order in a core-type power transformer is designed in the following way [3, 25]:

- The main windings are placed closer to the core and the Regulating winding is placed behind them to minimize the total mass of the winding system.

- The sum of the insulation distances between the main windings is minimal, if the Low Voltage is placed behind the core, which is in the ground potential, then the High Voltage winding is placed behind the Low Voltage.

It is generally known from the engineering practice that this winding order usually does not result in the cost optimal solution in case of autotransformer design. Therefore, the design of the autotransformer insulation system is handled as a different principle in the industry. As demonstrated in the introduction of the metaheuristic algorithm, the optimal value of a short circuit impedance is much lower than the required value. Thus, the SCI impedance requirement increases the TOC and modifies the geometrical parameters of the working window and the insulation system. The required SCI parameter is chosen according to the value of the nominal power. In case of autotransformers, the ratio of the built-in power and the nominal power is lower than one, about 0.5 . Therefore, the difference between the required and optimal ratios of the SCI in the case of autotransformers is higher than that of the normal power transformers. The following example shows how this overrated SCI requirement can lead to this different design principle (Fig. 5). This non-linearity effect is shown on a 200 MVA autotransformer.

The technical and economic parameters are the same as used in [9] for the validation of the metaheuristic algorithm. The purpose of this paper is to examine the dependence of TOC on SCI for the different winding layouts. Therefore, the required SCI parameter varies from $5.5 \%$ to $13.5 \%$. Fig. 6 shows the dependence of the optimal TOC on SCI. It can be seen from Fig. 6 that the LV-HV-Reg layout yields the cheapest design, till $11 \%$. Then the metaheuristic algorithm finds the optimal TOC values with increased main gap distance, till SCI is lower than $11.5 \%$. Here, the (LV-HVReg) optimal main gap distance value is nearly equal to $2 x$ main gap minimum plus the thickness of the Regulating winding. This is nothing else than the main gap thickness in the LV-Reg-HV case at the nominal tapping. From this point, the LV-Reg-HV layout yields the cost optimal solution for higher SCI requirements.

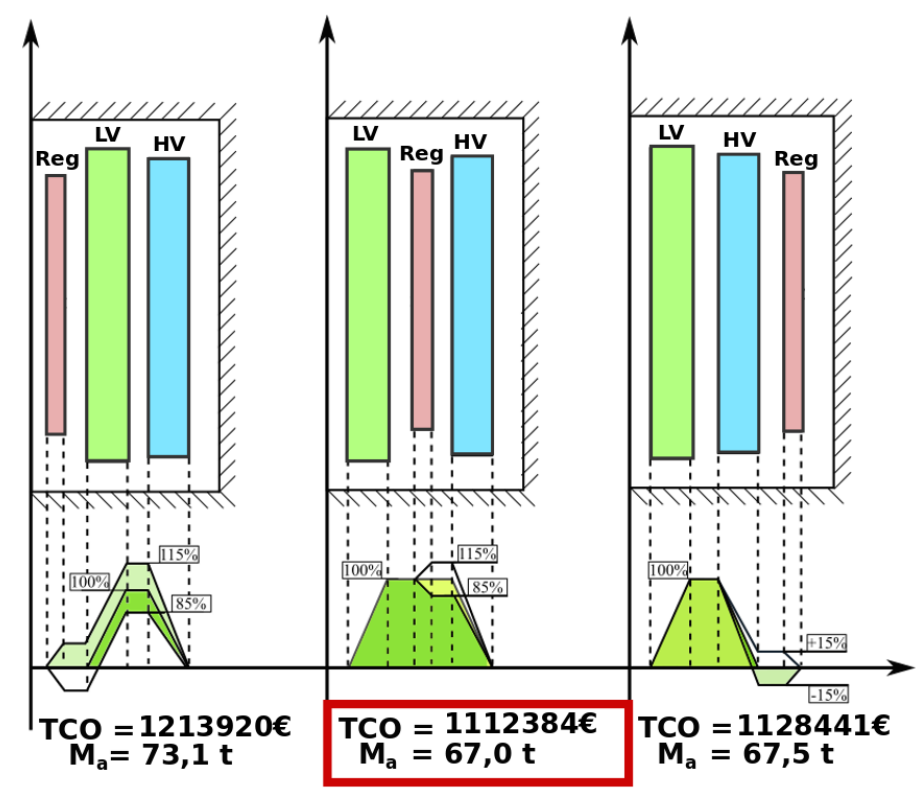

Fig. 5 The optimal value of the cost function and mass of the active parts are represented for three examined winding layouts. The value of the required short circuit impedance parameter is $13.5 \%$ in all depicted cases 


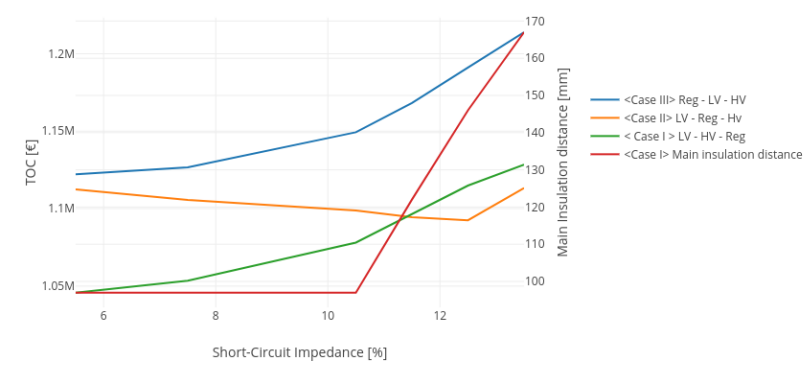

Fig. 6 The dependence of TOC on SCI requirement in three examined winding layouts and value of optimal main gap distance in case of the LV-HV-Reg layout

Therefore, the original SCI requirement is brought out by this layout instead of the LV-HV-Reg layout, which comes from the classical insulation volume minimization assumptions.

\subsection{Regulation type}

Generally, the turn-ratio of a modern large power transformer can be varied in a specific range. Hence, the low or the High Voltage terminals are equipped with some extra turns that may be added to, or subtracted from the electric circuit $[15,26]$. Different techniques have been used in the industry to vary the voltage of the tapped winding and, thereby, reactive power in the grid. This paper deals with the case when the High Voltage winding is regulated and examines the impact of the reversing and coarsefine arrangements on the TOC of the cost optimal design through the short-circuit impedance requirement [15]. For the sake of simplicity the following two-winding arrangement is considered, which is illustrated in Fig. 7. It is important to note that the applied cost optimization model neglects the cooling costs, thus it ensures that the cooling aspects have no effect on the results.

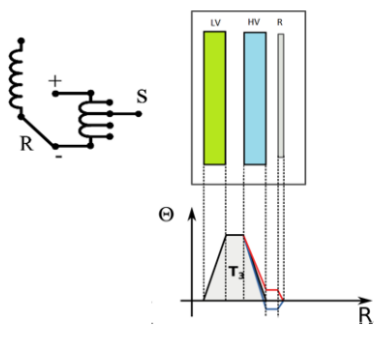

Reversing

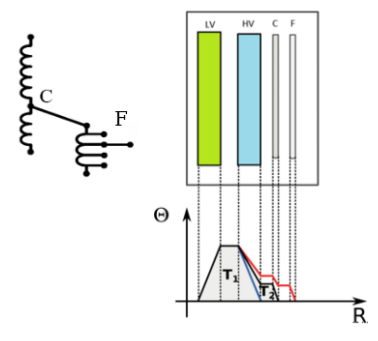

Coarse - Fine
Fig. 7 Typical winding arrangement and electrical connection scheme for reversing and coarse-fine regulations. Below these pictures, excitation diagram shows the difference between magnetic energy in normal tapping positions
The main advantage of the reversing arrangement is that the total number of the available positions is two times higher than the number of sections in the tapped winding plus one. Therefore, only one regulation winding is enough to realize the required tapping range. The following example deals with the widely used case, when the rated tapping position is the mid one. In this state, the whole tapped winding is de-energized. The main disadvantage of this regulation is that all the turns are active in the minimum voltage tapping, thus the cooling costs of the transformer are increased.

The coarse fine arrangement can be defined as a twostage linear regulation, where the whole coarse winding is active in the mid-tapping position. Generally, this coarse section contains as many turns as the fine winding plus one section $[15,26,27]$. The coarse stage can be turned on or off by a change-over selector (denoted as (C) in Fig. 8). The fine regulation is achieved by a selector switch (denoted by (F) in Fig. 8). The main benefit of this arrangement is that the coarse and the fine Regulating windings are inactive in the minimum tapping, and therefore, the cooling costs are smaller in this case than in case of the reversing arrangement [26, 27].

The following example deals with a $120 \mathrm{kV} / 20 \mathrm{kV}, 63 \mathrm{MVA}$ power transformer. The complete details of the examined transformer are presented in [15]. Typical values have been selected for the capitalization factors from [28]. The load loss capitalization cost in the examined case is $3533 € / \mathrm{kW}$ and the core loss capitalization is $7066 € / \mathrm{kW}$. The insulation distances were chosen by the widely used a priori empirical rules $[3,23,27,29,30]$. These insulation distance selection

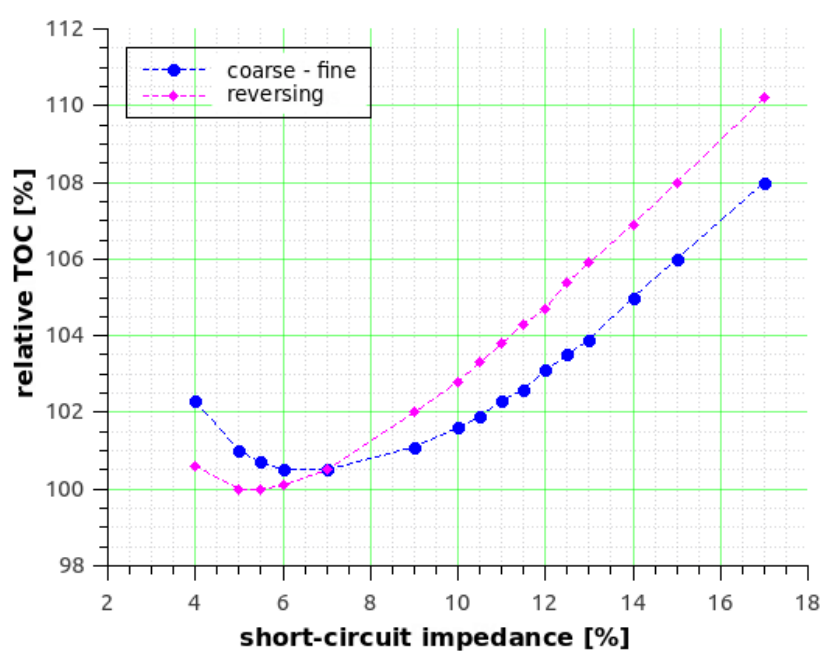

Fig. 8 Dependence of relative TOC on SCI in case of two different regulation types 
methods were based on the lightning impulse and AC test prescription and recommend to use the minimal insulation distances for the given economic scenario.

In this example, the transformer optimization was performed with different short circuit impedance requirements from $4 \%$ to $17 \%$ for the reversing and coarse fine regulations separately. The results of the optimization are shown in Fig. 8. The SCI value has a minimum value as it can be seen from the results. The optimum value of the TOC is smaller in the case of reversing arrangement consistently with the classical design rules.

Moreover, the optimal value of the TOC is shifted to the right along the short circuit impedance axes (Fig. 8) by approximately $2 \%$. This difference is coming from the impact of the active coarse winding on the short circuit impedance. The other, more important result of this active coarse winding is that in the case of higher short-circuit impedance values the value of the optimal TOC is by $2-4 \%$ lower than in case of the reversing case. This means that in this example, instead of the coarse-fine regulation requiring more windings, it is more economical than the reversing arrangement.

\section{References}

[1] Abetti, P. A., Cuthbertson, W. J., Williams, S. B. "Philosophy of Applying Digital Computers to the Design of Electric Apparatus", Transactions of the American Institute of Electrical Engineers, Part I: Communication and Electronics, 77(3), pp. 367-379, 1958. https://doi.org/10.1109/TCE.1958.6372814

[2] Orosz, T., Kleizer, G., Iváncsy, T., Tamus, Z. Á. "Comparison of Methods for Calculation of Core-Form Power Transformer's Core Temperature Rise", Periodica Polytechnica Electrical Engineering and Computer Science, 60(2), pp. 88-95, 2016. https://doi.org/10.3311/PPee.8893

[3] Karsai, K., Kerényi, D., Kiss, L. "Large power transformers", Akadémiai Kiadó, Budapest, Hungary, 1987.

[4] Orosz, T. "Evolution and Modern Approaches of the Power Transformer Cost Optimization Methods", Periodica Polytechnica Electrical Engineering and Computer Science, 63(1), pp. 37-50, 2019. https://doi.org/10.3311/PPee.13000

[5] Olivares-Galvan, J. C., Georgilakis, P. S., Fofana, I., MagdalenoAdame, S., Campero-Littlewood, E., Esparza-Gonzalez, M. S. "A bibliographic analysis of transformer literature 2001-2010", In: 8th Mediterranean Conference on Power Generation, Transmission, Distribution and Energy Conversion (MEDPOWER 2012), Cagliari, Italy, 2012, pp. 1-6. https://doi.org/10.1049/cp.2012.2043

[6] Orosz, T., Poór, P., Karban, P., Pánek, D. "Power Transformer Design Optimization for Carbon Footprint", In: 2019 Electric Power Quality and Supply Reliability Conference (PQ) \& 2019 Symposium on Electrical Engineering and Mechatronics (SEEM), Kärdla, Estonia, 2019, pp. 1-4. https://doi.org/10.1109/PQ.2019.8818261

\section{Conclusions}

Investigating the effect of insulation system on the key design parameters of an autotransformer, the result shows that — in contrast with the classical insulation design rule - the optimization of the insulation volume does not lead to the cost optimized transformer design in every case. Similarly, the tap-changing selection and the place of Regulating winding also have effect on the optimal preliminary design of an electrical machine. Next to numerous other advantages, the coarse-fine regulated transformer can be cheaper than the reversing arrangement above a short circuit impedance value in a given economic environment. The results of the paper proposes involving more cost-critical parameters in the preliminary design phase of electrical machines is indispensable due to the intense competition in the electrical equipment market. The increased parameter number requires new optimization techniques for supporting the fast decision making in the preliminary design process. The newly developed metaheuristic algorithm can provide proper results in acceptable time even for large number of the input parameters.

[7] Poór, P. "Strenghtening of Boundary Processes in a Company Using Specific Computer-aided Facility Management Software", In: 2014 IEEE 12th International Symposium on Applied Machine Intelligence and Informatics (SAMI), Herl'any, Slovakia, 2014, pp. 257-261. https://doi.org/10.1109/SAMI.2014.6822418

[8] Orlova, S., Rassõlkin, A., Kallaste, A., Vaimann, T., Belahcen, A. (2016) "Lifecycle Analysis of Different Motors from the Standpoint of Environmental Impact", Latvian Journal of Physics and Technical Sciences, 53(6), pp. 37-46, 2017. https://doi.org/10.1515/lpts-2016-0042

[9] Pánek, D., Orosz, T., Karban, P. "Artap: Robust Design Optimization Framework for Engineering Applications", In: 2019 Third International Conference on Intelligent Computing in Data Sciences (ICDS), Marrakech, Morocco, 2019, pp. 1-6. https://doi.org/10.1109/ICDS47004.2019.8942318

[10] Orosz, T., Sleisz, Á., Tamus, Z. Á. "Metaheuristic Optimization Preliminary Design Process of Core-Form Autotransformers", IEEE Transactions on Magnetics, 52(4), Article number: 8400310, 2016. https://doi.org/10.1109/TMAG.2015.2496905

[11] Orosz, T., Borbély, B., Tamus, Z. Á. "Performance Comparison of Multi Design Method and Meta-Heuristic Methods for Optimal Preliminary Design of Core-Form Power Transformers", Periodica Polytechnica Electrical Engineering and Computer Science, 61(1), pp. 69-76, 2017. https://doi.org/10.3311/PPee.10207

[12] Georgilakis, P. S. "Spotlight on Modern Transformer Design", Springer-Verlag London, London, UK, 2009. https://doi.org/10.1007/978-1-84882-667-0 
[13] Orosz, T., Sleisz, Á., Tamus, Z. Á. "Metaheuristic Optimization Preliminary Design Process of Core-Form Autotransformers", IEEE Transactions on Magnetics, 52(4), Article number: 8400310, 2016. https://doi.org/10.1109/TMAG.2015.2496905

[14] Orosz, T., Sleisz, A., Vajda, I. "Core-form transformer design optimization with branch and bound search and geometric programming", In: 2014 55th International Conference on Power and Electrical Engineering of Riga Technical University (RTUCON), Riga, Latvia, 2014, pp. 17-21. https://doi.org/10.1109/RTUCON.2014.6998194

[15] Orosz, O., Tamus, Z. Á. "Impact of short-circuit impedance and tap changing method selection on the key-design parameters of core-form power transformers", Electrical Engineering, 100(3), pp. 1631-1637, 2018. https://doi.org/10.1007/s00202-017-0642-z

[16] Boyd, S. Vandenberghe, L. "Convex Optimization", Cambridge University Press, Cambridge, UK, 2004. https://doi.org/10.1017/CBO9780511804441

[17] Boyd, S., Kim, S.-J., Vandenberghe, L., Hassibi, A. "A tutorial on geometric programming", Optimization and Engineering, 8(1), Article number: 67, 2007. https://doi.org/10.1007/s11081-007-9001-7

[18] Jabr, R. A. "Application of Geometric Programming to Transformer Design", IEEE Transactions on Magnetics, 41(11), pp. 4261-4269, 2005 https://doi.org/10.1109/TMAG.2005.856921

[19] Lopez-Fernandez, X. M., Alvarez-Mariño, C., Couto, D., Lopes, R., Jacomo-Ramos, A. "Modeling and Insulation Design Methodology in Power Transformer under Fast Transients", In: The XIX International Conference on Electrical Machines ICEM 2010, Rome, Italy, 2010, pp. 1-6. https://doi.org/10.1109/ICELMACH.2010.5608019

[20] Németh, E., Horváth, T. "Nagyfeszültségủ szigeteléstechnika" (High Voltage Insulation Technique), Tankönyvkiadó Vállalat, Budapest, Hungary, 1976. (in Hugarian)

[21] Capuder, K., Janić, Ž., Štih, Ž. "Analyzing Method Efficiency for Power Transformers Insulation Design", In: Eurocon 2013, Zagreb, Croatia, 2013, pp. 1542-1547. https://doi.org/10.1109/EUROCON.2013.6625183
[22] Montanari, G.C."Envisaging Links between Fundamental Research in Electrical Insulation and Electrical Asset Management", IEEE Electrical Insulation Magazine, 24(6), pp. 7-21, 2008. https://doi.org/10.1109/MEI.2008.4665346

[23] Ryan, H. M. "High Voltage Engineering and Testing", IET, Stevenage, UK, 2013. https://doi.org/10.1049/PBPO066E

[24] IEEE Standards Association "C57.120-2017 IEEE Guide for Loss Evaluation of Distribution and Power Transformers and Reactors", IEEE, New York, NY, USA, 2017. https://doi.org/10.1109/IEEESTD.2017.8103991

[25] Kulkarni, S. V., Khaparde, S. "Transformer Engineering: Design, Technology, and Diagnostics", CRC Press, Taylor \& Francis Group, Boca Raton, FL, USA, 2016.

[26] White, A. "Tapchanging - the Transformer Designer's Perspective", In: IEE European Seminar on Developments On-Load Tapchangers: Current Experience and Future, Regensburg, Germany, 1995, pp. $4 / 1-4 / 6$. https://doi.org/10.1049/ic:19951239

[27] Del Vecchio, R. M., Poulin, B., Feghali, P. T., Shah, D. M., Ahuja, R. "Transformer Design Principles: With Applications to Core-Form Power Transformers", CRC Press, Boca Raton, FL, USA, 2010. https://doi.org/10.1201/EBK1439805824

[28] Orosz, T., Sőrés, P., Raisz, D., Tamus, Z. Á. "Analysis of the Green Power Transition on Optimal Power Transformer Designs", Periodica Polytechnica Electrical Engineering and Computer Science, 59(3), pp. 125-131, 2015. https://doi.org/10.3311/PPee.8583

[29] Kulkarni, S. V., Khaparde, S. "Transformer Engineering: Design and Practice", Marcel Dekker, Inc., New York, NY, USA, 2004.

[30] Mustafa, E., Tamus, Z. Á., Afia, R. S. A., Asipuela, A. "Thermal Degradation and Condition Monitoring of Low Voltage Power Cables in Nuclear Power Industry", In: Doctoral Conference on Computing, Electrical and Industrial Systems, Costa de Caparica, Portugal, 2019, pp. 405-413. https://doi.org/10.1007/978-3-030-17771-3 35 